\title{
TRM REINFORCEMENT OF MASONRY SPECIMENS FOR SEISMIC AREAS
}

\author{
S. IVORRA ${ }^{1}$, D. BRU ${ }^{1}$, A. GALVAÑ ${ }^{1}$, STEFANO SILVESTRI $^{2}$, CRISTINA APERA $^{2} \&$ DORA FOTI $^{3}$ \\ ${ }^{1}$ Civil Engineering Department, University of Alicante, Spain. \\ ${ }^{2}$ Dipartimento di Ingegneria Civile, Chimica, Ambientale e dei Materiali, Unversità di Bologna, Italy. \\ ${ }^{3}$ DICAR, Politecnico di Bari, Italy.
}

\begin{abstract}
This document analyses the resistant behaviour to diagonal compression and direct compression of brick masonry specimens, reinforced with textile reinforced mortars (TRM) and without them. The numerical models have been calibrated with experimental results in order to have a suitable technique to reinforce masonry historic constructions where extraordinary tension stresses could occur in seismic situations. For the numerical modelling, FEM models have been developed using non-linear layered bi-dimensional shell elements. Moreover, a comparative analysis has been developed between the numerical models and the experimental ones. There are two different types of reinforced specimens: two layers to reinforce both surfaces (i), and one layer for only one surface (ii). The point of this (ii) is to respect the Italian legislation indications for the protection of historic constructions.
\end{abstract}

Keywords: reinforced masonry TRM walls FEM

\section{INTRODUCTION}

Many residential areas in the historical centres of European Seismic areas have a very high vulnerability due to of their structural system based in masonry or brick masonry walls. These structures have a very low capacity to resist tension or shear stresses. The use of textile reinforced mortar (TRM) as a reinforcing element can provide an additional capacity to solve these structural problems. Mortar cementitious materials as matrix of these reinforcement systems are more compatible with masonry than other polymeric matrices where its use in historical constructions is not permitted by the authorities in charge of protecting these constructions.

Brick masonry walls are building systems made up of brick elements joined by mortar with a specific disposition. Due to its configuration, with elements of different properties, their simulation by finite element method becomes a complicated task. Brick and mortar have different strength capacities, and the very different strength behaviour in tension and in compression generates an anisotropic behaviour. Another important factor is the influence of the elastic modulus of both materials. By having different elastic modulus, their strain, for a given stress, will be different and the compatibility equations should solve this interaction. For these reasons, the ultimate load behaviour of brick masonry specimens are very dependent on the direction of the applied load and the plane on which the loads act.

Some studies, such as those carried out at the Polytechnic University of Catalonia [1], analyse the out-of-plane behaviour, although the present paper will only focus on the loads acting on the plane of the wall. Masonry structures are especially weak against lateral cyclic loads such as those caused by earthquakes and this work analyses them. The difference of elastic modulus and the differences between the maximum stresses in tension and compression for brick and mortar are the cause of the specimen fault in the weakest areas of the wall. It is necessary to understand that the weakest areas will be the joints between the bricks: the mortar. These joints are in charge of the masonry specimens' cohesion. Many authors have tried to define the properties of the masonry walls against vertical, horizontal, in plane or out 
of plane loads, in order to be able to characterize the existing ones, since this type of construction has fallen into disuse for new constructions. At present, some research lines focus on the reinforcement of these constructions, generally of historical character, for different types of loads, being able to find a variety of reinforcements from bars or steels meshes to laminated materials of diverse nature Ref. [2-6].

The modelling of masonry walls with finite element models such as those performed by several authors Ref. [7-13] has allowed a qualitative leap in the field. In this case, simple FEM models will be developed in order to create a model to be use it in large structural models of complete constructions. In this paper, a numerical study will be carried out using the SAP2000 program [14] as a preliminary phase to develop an experimental campaign in the Civil Engineering Laboratory at the University of Alicante. For these models, the masonry wall specimens have been modelled under different load cases (diagonal compression and simple compression), characterizing them properly, to provide a relatively simple and sufficiently approximated to reality calculation model. In addition, models of masonry walls with fiberglass reinforced mortar (TRM) have been made in order to obtain adequate approximation values and to estimate the improvements provided by this type of reinforcement, applying to the walls in both surfaces as in one.

TRM reinforcement may be implemented according to two different procedures: (i) the double layer one, and (ii) the single layer one. The use of a single layer is frequently imposed by the Italian Regional Boards of the Ministry of Cultural Heritage to preserve the memory of the facades of historic buildings, by imposing the reinforcement only in the inner face. These models have been carried out by taking into account the values of real experimental tests in order to have an approximate idea of whether the numerical calculations are sufficiently approximate or not. Other results of experimental articles have also been contrasted $[15,16]$.

\section{METHODOLOGY AND MATERIAL CHARACTERIZATION}

\subsection{Geometric definition of masonry walls and reinforcement}

The selected geometry for the numerical compression model is developed according to the proposal of DIN EN 1052-1:1998-12 [17]. With this geometry, the results of numerical and the future experimental tests can be compared. Figure 1 shows the geometry.

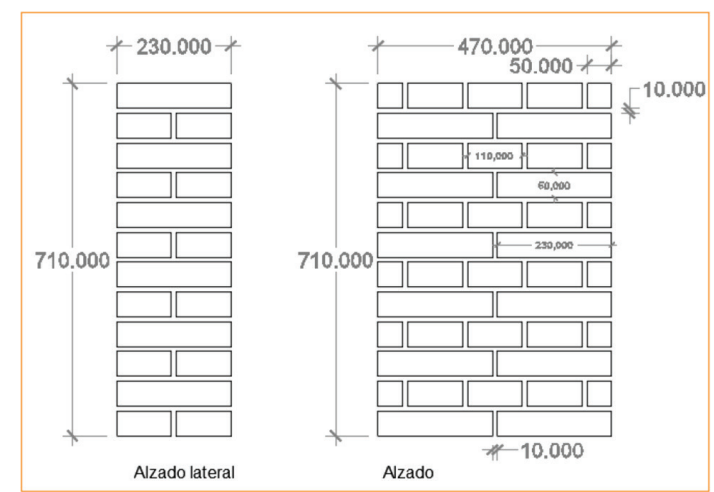

Figure 1: Geometry of the compression specimen (mm). 

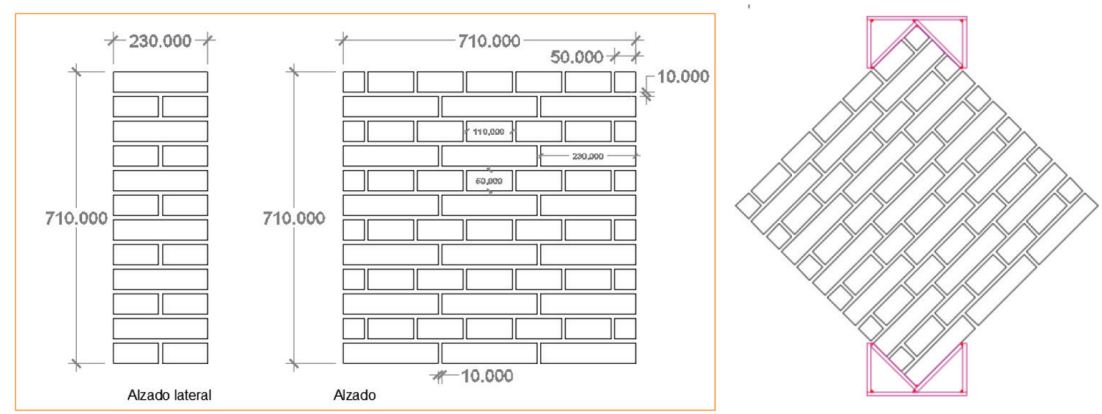

Figure 2: Diagonal Compression specimen's geometry (left) and test configuration (right).

The selected geometry for the numerical diagonal compression model (Fig. 2) has been developed according to the indications of ASTM E519/E519M. 2010 [18].

Two TRM layers - one at each side of each masonry specimen - have been considered for the reinforcement. The general procedure for each TRM layer is:

- Mortar with a 10-mm thick layer in the whole surface (in the simulation, the mechanical characteristics of Mapei Planitop HDM Restoration have been considered).

- Fiberglass in mesh form at 0 and 90 degrees established in the middle thickness of the reinforcing mortar (Mapegrid G220).

\subsection{Failure criterion}

The failure criterion used by SAP2000 [14] is the Mohr-Coulomb failure criterion (Ec. 1), in which two terms are considered:

- A first term, which is a function of the normal stress applied perpendicular to the shear strength and a function of the internal friction angle of the masonry material.

- A second term, which, in this case, is the cohesion of the masonry material.

$$
\tau=\sigma^{*} \tan \theta+c
$$

\subsection{Model properties}

To model unreinforced masonry specimens, non-linear layered shell elements have been considered. To simulate the masonry specimens two non-lineal layers have been used in these shells:

- A first layer, called the friction layer, to simulate the behaviour to normal stresses (S11 and S22 -horizontally and vertically within the plane, respectively -), as well as the first failure criterion term of Mohr-Coulomb failure criterion. S11 and S22 stresses will have the nonlinear behaviour showed in Fig. 3. S12 is inactive.

- A second layer, called cohesion layer, responsible for providing the shear strength due to the cohesion of the wall, which would be the second addend to the criterion discussed above. S11 and S22 stresses will be inactive and in S12 will have the non-linear characteristics showed in Fig. 4. 


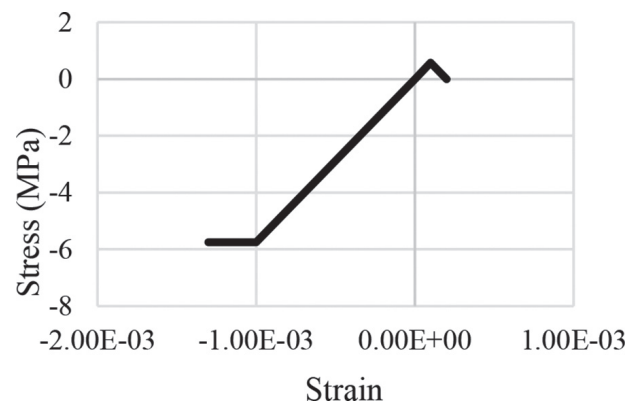

Figure 3: Masonry behaviour for the friction layer S11-S22 (Units: MPa).

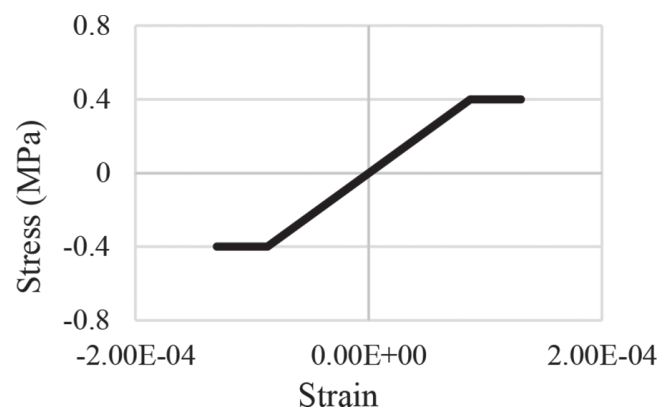

Figure 4: Masonry behaviour for the cohesion layer S12 (Units: MPa).

\subsubsection{Compression test}

For reinforced masonry walls, additional layers have been added to the layered shell elements. Two different models have been developed to compare their capability to simulate the real tests:

i. Fiber mesh reinforcing has been considered as continuous layer with a thickness of $0.035 \mathrm{~mm}$.

ii. Fiber mesh reinforcing has been considered like a rebar mesh using the effective dimension of the Mapegrid G220.

\subsubsection{Diagonal compression}

For reinforced models, two/four layers have been used depending on whether the model was reinforced, on one/two sides:

- A layer where mortar with non-linear behaviour will be introduced in all directions (S11S22-S12). This layer will be situated at a distance from the axis of half the wall thickness without reinforcing plus half the mortar layer thickness (Fig. 5).

- Another layer for the fiberglass mesh with non-linear characteristics in S11 and S22 and inactive in S12 placed at a distance from the axis of half of the thickness of the wall without reinforcing plus half the thickness of the layer of mortar and half of the fiber thickness (Fig. 6).

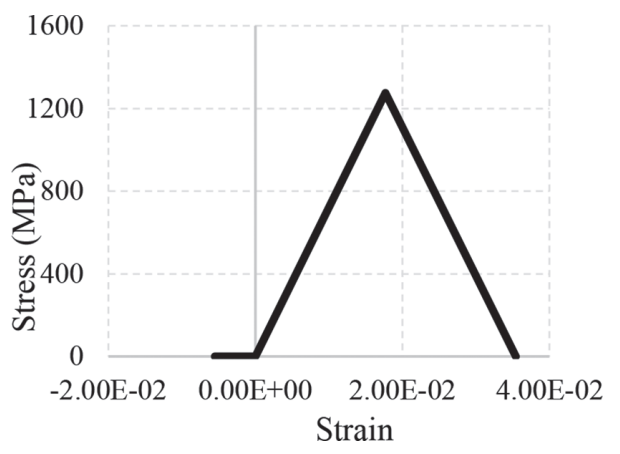

Figure 5:Fiberglass reinforcing mesh, stressstrain behaviour (Units: MPa).

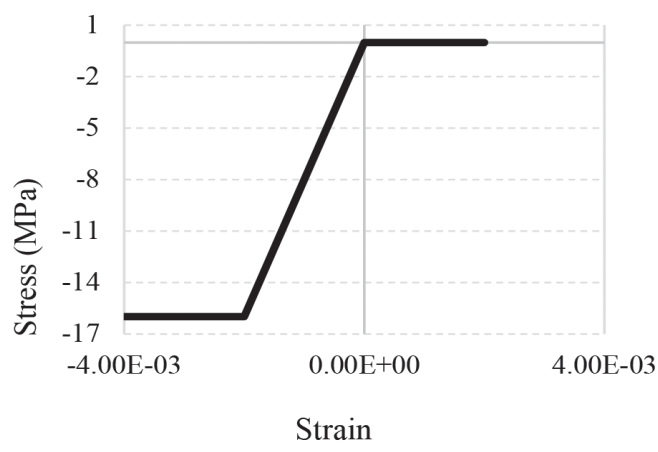

Figure 6: Reinforcing mortar, stress-strain behaviour (Units: MPa). 
Table 1: Material properties

\begin{tabular}{llllll}
\hline & \multicolumn{5}{c}{ Properties } \\
\cline { 2 - 6 } Materials & $\mathrm{f}_{\mathrm{ck}}(\mathrm{MPa})$ & $\mathrm{E}(\mathrm{MPa})$ & $\mathrm{f}_{\mathrm{t}}(\mathrm{MPa})$ & $\mathrm{G}(\mathrm{MPa})$ & $\tau(\mathrm{MPa})$ \\
\hline Brick & 15.00 & - & - & - & - \\
Mortar & 4.50 & - & - & - & - \\
Masonry & 5.75 & 5750 & 0.57 & 2300 & 0.20 \\
\hline
\end{tabular}

\subsection{Material definition}

\subsubsection{Masonry material}

\subsubsection{Reinforcing materials}

The characteristics for the mortar used in the reinforcement have been provided by the manufacturer Mapei for their mortar Planitop HDM Restoration, and the characteristics for the mesh used in the reinforcement have been provided by the manufacturer Mapei for their product Mapegrid G220:

\section{SPECIMENS MODELLED FOR THE SIMULATED TEST}

\subsection{Compression test}

The models for simple compression are based on the use of linear and non-linear shell elements, alternating themselves vertically, with the purpose of having a symmetrical section. The non-linear shell elements are located where failure can occur. All models use layered shell elements of the maximum size of $24 \mathrm{~mm}$. The boundary conditions for all the nodes in the base are pinned connections. For the top of the specimen, free displacements are considered for all nodes (Fig. 7).

For the linear layer, fiber and mortar have been considered with linear behavior in S11 and $\mathrm{S} 22$, inactive in S12. Instead in the non-linear section they have non-linear behavior in S11 and $\mathrm{S} 12$, inactive in $\mathrm{S} 12$.

Table 2: Reinforcing material properties

\begin{tabular}{llllllll}
\hline & \multicolumn{8}{c}{ Properties } \\
\cline { 2 - 7 } & & \multicolumn{7}{c}{$\begin{array}{l}\text { Resh size } \\
\text { per unit length } \\
\left(\mathrm{mm}^{2} / \mathrm{m}\right)\end{array}$} & $\begin{array}{l}\text { Tensile strength } \\
\text { per unit length } \\
(\mathrm{kN} / \mathrm{m})\end{array}$ \\
\hline $\begin{array}{l}\text { Materials } \\
\begin{array}{l}\text { Reinforcing } \\
\text { mortar }\end{array}\end{array}$ & 8000 & 16 & 1900 & - & - & - & - \\
$\begin{array}{l}\text { Fiberglass } \\
\text { mesh }\end{array}$ & 72000 & - & 2500 & 1.80 & $25 \times 25$ & 35.27 & 45 \\
\hline
\end{tabular}



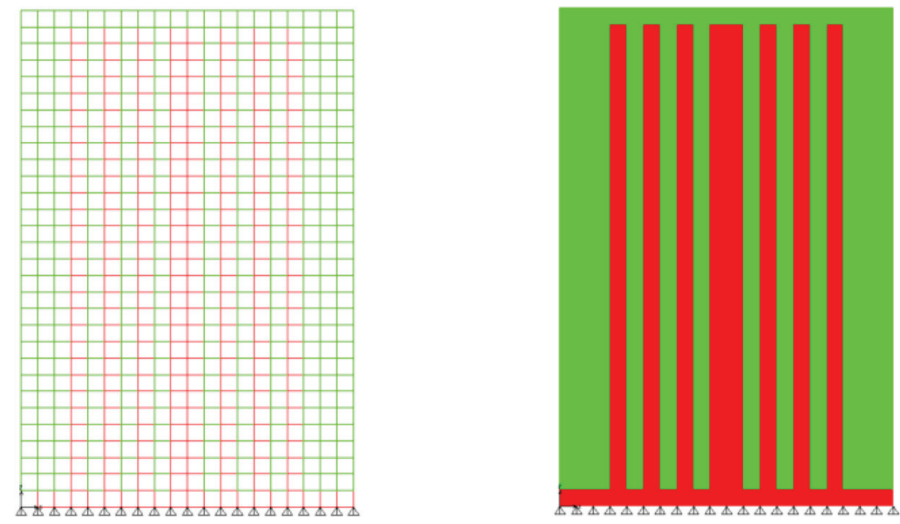

Figure 7: Numerical model of brick masonry wall for compression test. Left: Mesh. Right: layers, red nonlinear, green linear.

\subsection{Diagonal compression}

To develop a numerical model for the diagonal compression test, some restrictions are imposed both at the top and at the bottom, as well as the 45 degree rotated speciment. Restrictions have been placed distributedly at the top and at the bottom to avoid local stresses on the shell elements and do that an undesirable type of breakage does not occur (Fig. 8).

In the lower part, recesses have been established and in the upper one only the displacement in the vertical direction or $\mathrm{Z}$ axis has been allowed, applying a target displacement in the upper point. In addition, the local axes of the shells have been rotated 45 degrees.

\section{RESULTS}

A nonlinear quasi static load test has been developed controlling the vertical displacement of a top symmetric node in each specimen, for the compression model and for the diagonal compression model.
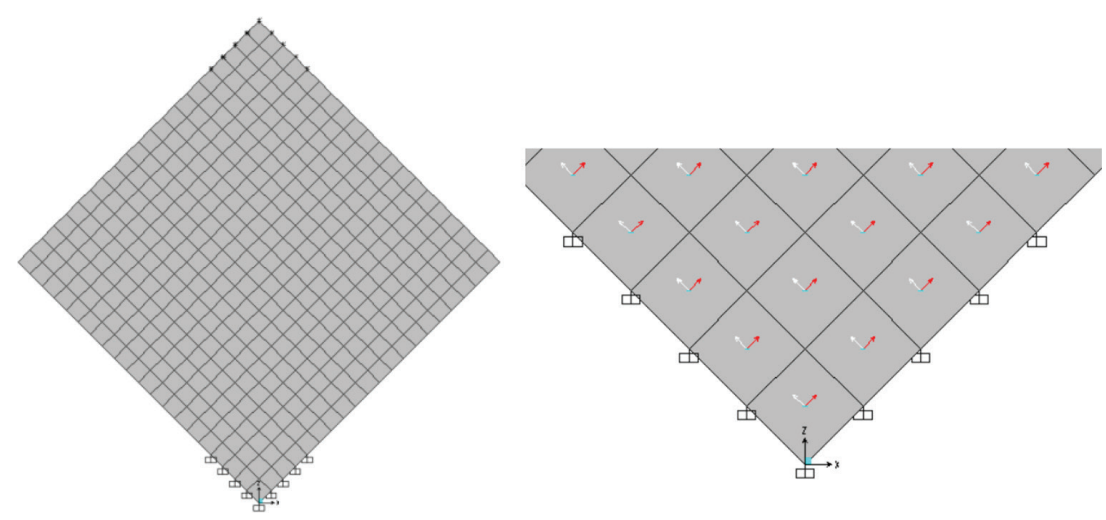

Figure 8: Numerical model of brick masonry wall for diagonal compression test and detail of the shell element local axes. 


\subsection{Compression results}

The model shows the elastic behaviour and the Poisson effect during all the loading process (Fig. 9).

Analysing the results of the reinforced masonry specimens some stages can be detected. Initially, glass fiber mesh does not start to work in tension until the breakage of the masonry wall occurs (Fig. 10).

In a second stage, when the masonry specimen is broken, the glass fiber mess starts to work in tension reinforcing the specimen (Fig. 10).

Figure 11 shows the increment of the ultimate compression load and the ductility of the reinforced specimen. The glass fiber mesh is the source of that small increment on the ultimate load.

Figure 12 shows the deformed model, with and without reinforcing fiber glass mesh. The showed (Fig. 12, right) specimen has two layers reinforcing the masonry specimen, one at each side, of the masonry unit.
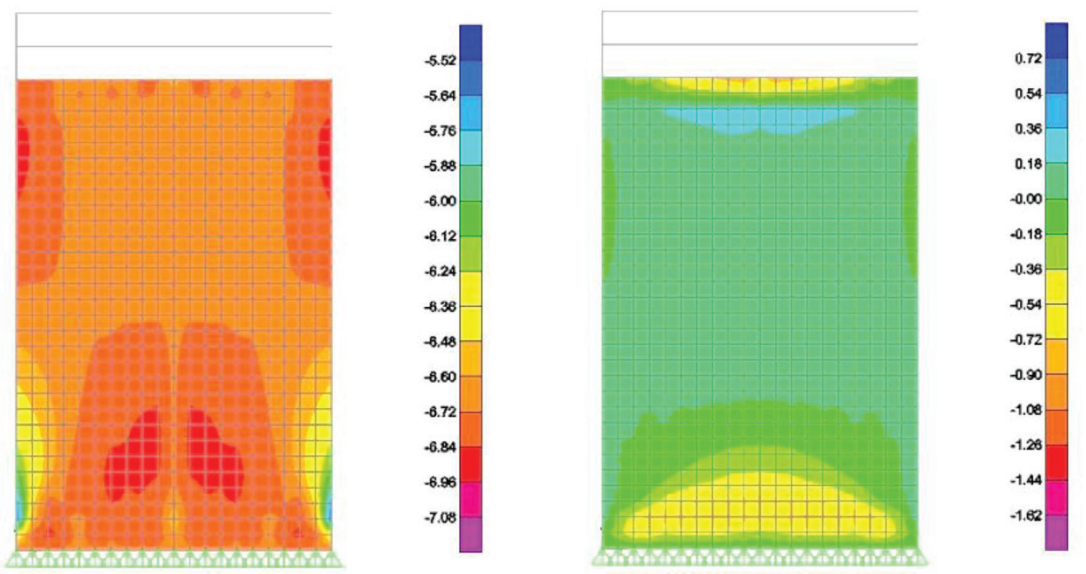

Figure 9: Brick masonry specimens. Numerical results for the compression test. Left: Vertical Compression stresses (S22). Right: Tension stress (S11). (Units: MPa).
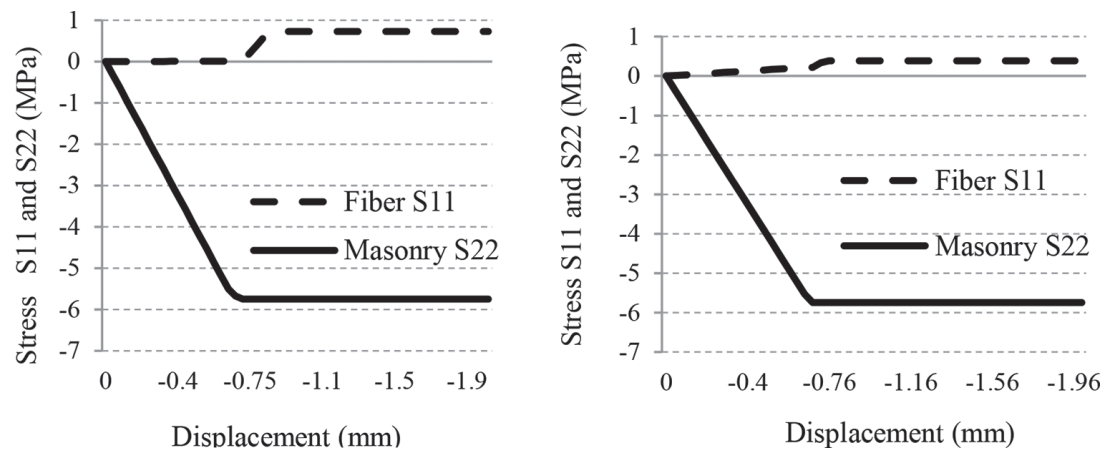

Figure 10: Stress vs displacement curve. Reinforced masonry specimen under compression loads. Left: Reinforcement modelled as continuous shell. Right: Reinforcement modelled as rebar mesh. (Units MPa-mm). 


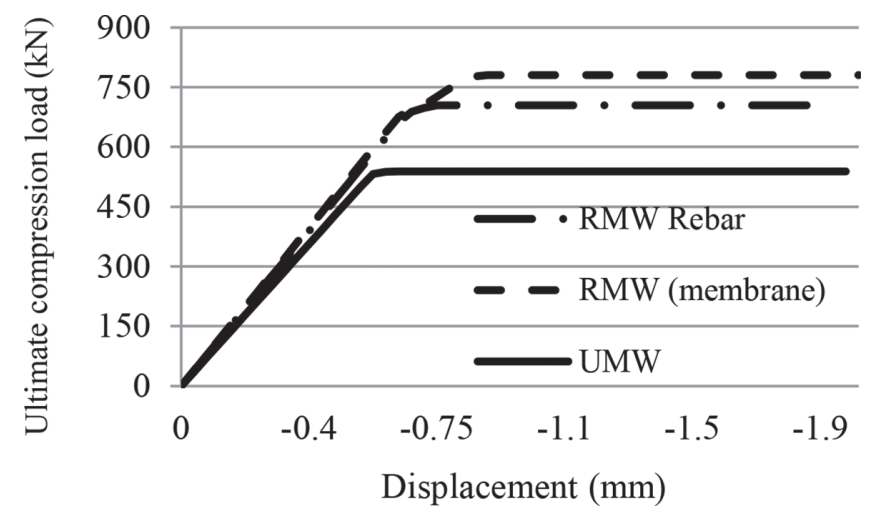

Figure 11: Base shear and displacement in the middle and in the upper point of the wall respectively (Units: $\mathrm{kN}-\mathrm{mm}$ ).
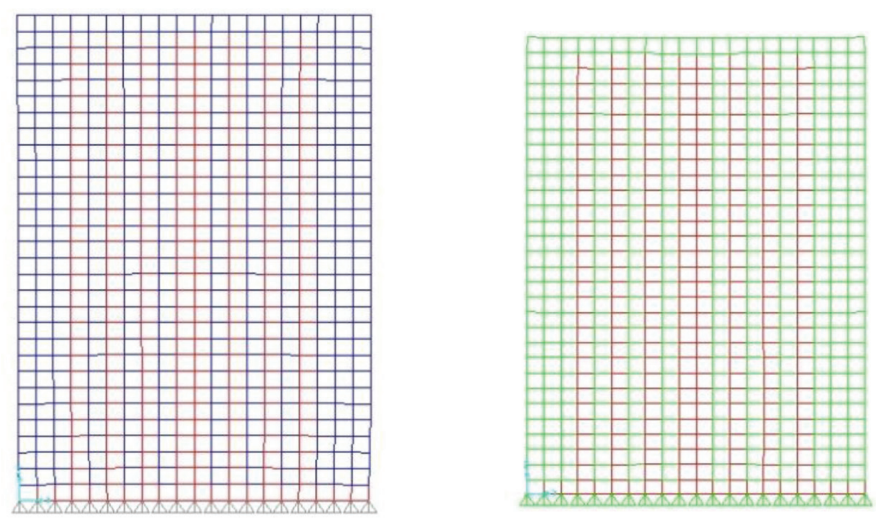

Figure 12: Deformation of the masonry specimen at the moment of the breakage. Left: unreinforcement. Right: 2 sides reinforced (glass fiber as a layer).

\subsection{Diagonal compression results}

In the development of this test it was possible to observe how the wall was compressed until it reached a sudden breakage diagonally, and with this, some sudden tensile efforts in that area. In the following image, representative of the S22 stresses in the brick wall, it is shown the wall compressed state and the breakage beginning (Figs. 13-16).

In the following image, for the reinforced two-surface model, we can observe how the layer of the fiber starts having no stress in S22 and then starts to work in traction. This way of working of the reinforcement, as well as its breakage, is similar to that studied by other authors from the University of Nizwa [5].

All this can be observed with more precision in the Fig.15, perceiving the breakage of the brick factory and the loading of the TRM reinforcement.

Moreover, Fig. 17 shows a comparison between the horizontal displacements of two specimens when a vertical load is applied. The use of one-surface to reinforce the model does not show the expected precision because it is working with a model of shell elements which does 

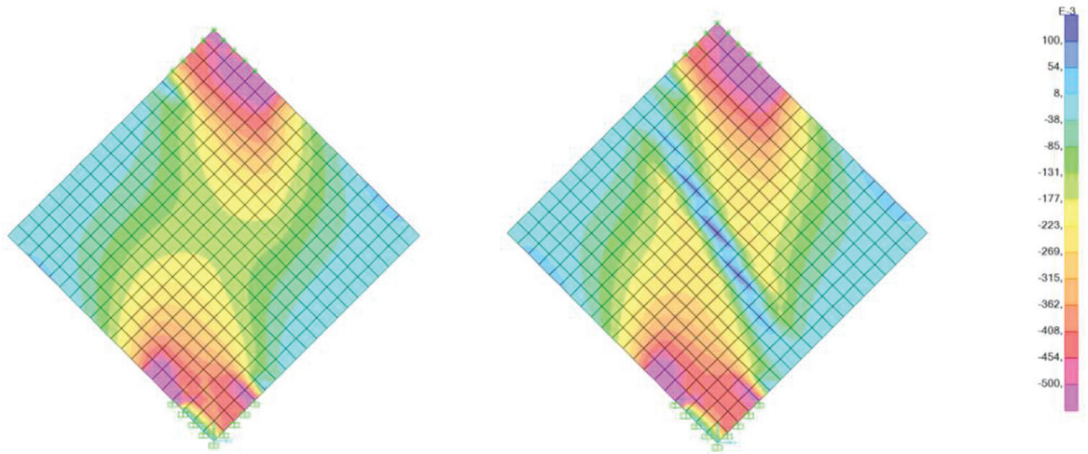

Figure 13: S22 stresses in the wall layer. On the left, compressions before breakage; to the right, breakage of the wall and tensile crack. (Units: MPa).
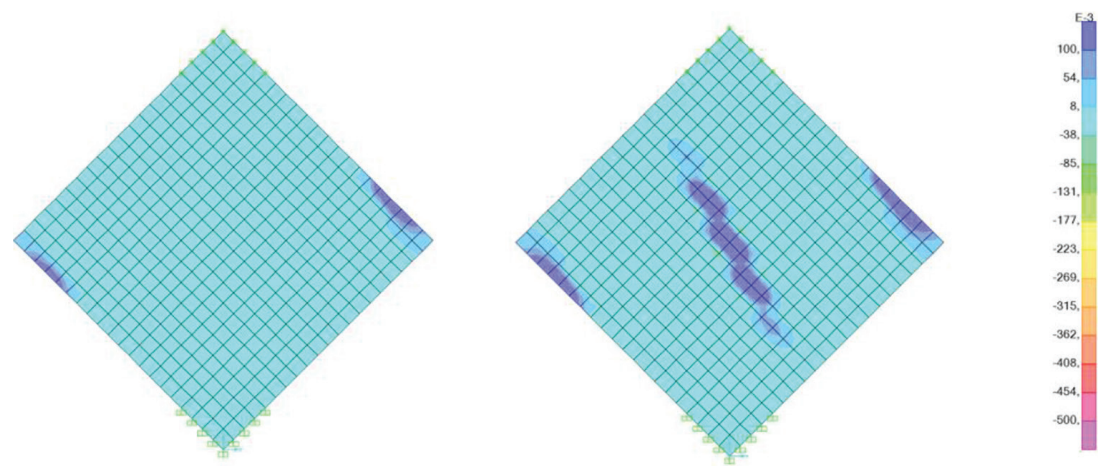

Figure 14: S22 stresses in the fiber layer. Left, fiberglass mesh without entering in charge; right, fiberglass mesh starts to work once the masonry wall cracks. (Units: MPa).

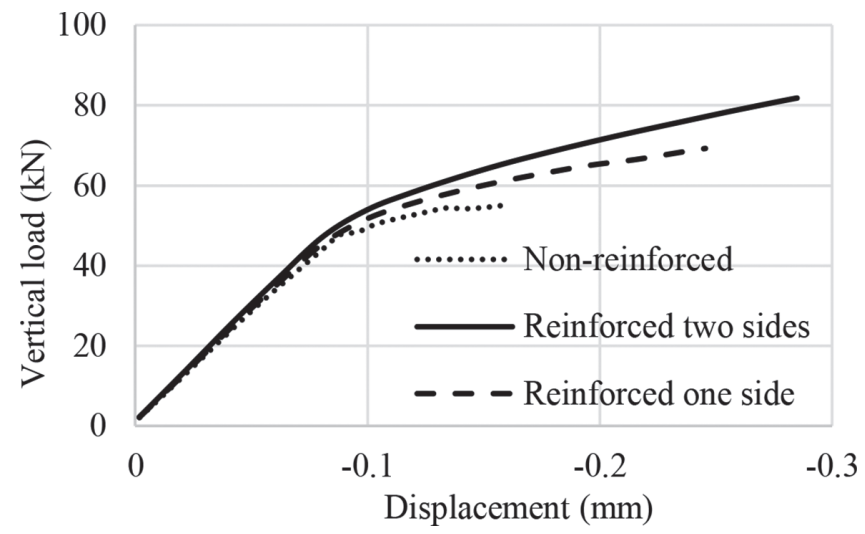

Figure 15: Base loads vs vertical top displacement. (Units: $\mathrm{kN}-\mathrm{mm}$ ). 


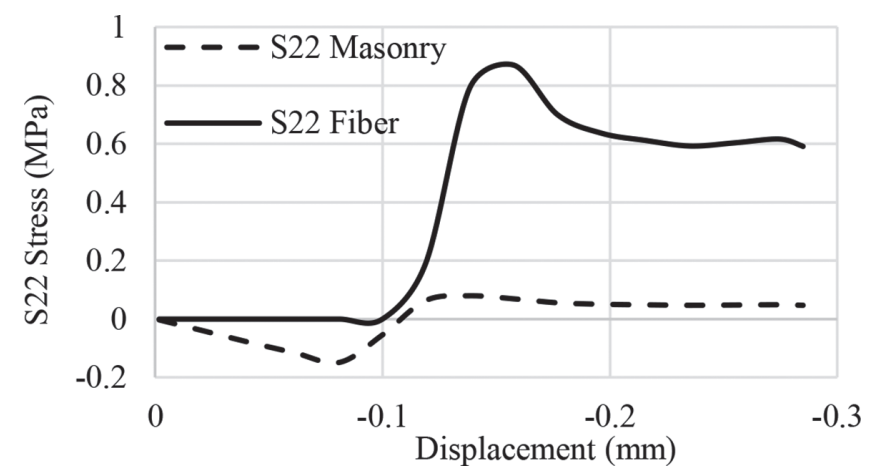

Figure 16: S22 stresses vs vertical top displacement. (Units: MPa-mm)
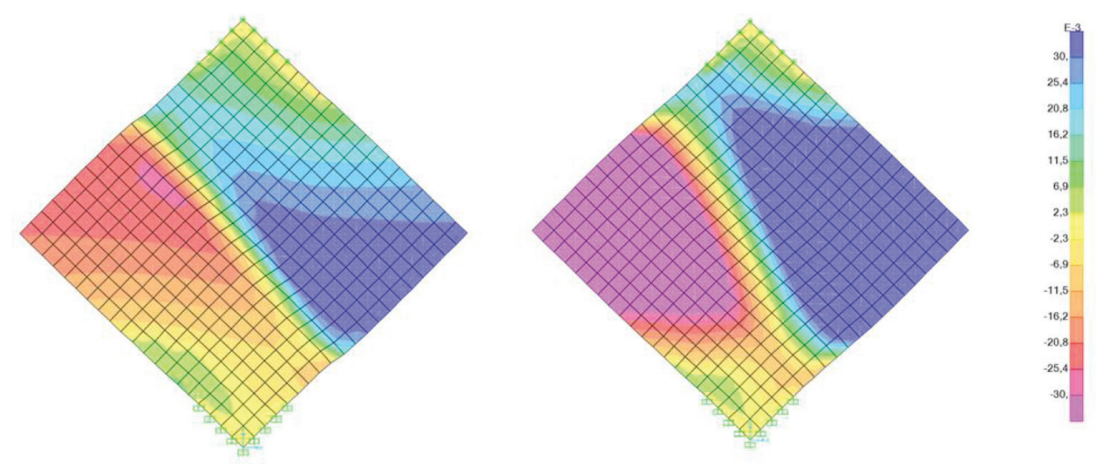

Figure 17: Deformed shape. Left: Specimen without reinforcing; right: Double-sided reinforced masonry specimen. $(\mathrm{mm})$

not consider the asymmetry but the perfect contact surfaces between wall and reinforcement.

Observing the unreinforced wall deformed shape as well as the reinforced on two sides deformed shape, we can see how the reinforcement allows to reach bigger displacements in the specimens.

\section{CONCLUSIONS}

The model created with the finite element software SAP2000 [14] using non-linear shell-layered elements has proved to be a valid technique to simulate masonry specimens reinforced with TRM.

With this preliminary analysis, through the appropriate calibrations with experimental results, an accurate maximum capacity of specimens reinforced with TRM can be obtained. This model allows to professional engineers to have a simple calculation tool for modelling structures that have generally required more powerful software to obtain consistent results.

This technique allows to model historical structures under seismic loads in order to know the reinforcement necessary to be able to resist these loads. 


\section{REFERENCES}

[1] Bernat-Maso, E., Gil, L. \& Roca, P., Numerical analysis of the load-bearing capacity of brick masonry walls strengthened with textile reinforced mortar and subjected to eccentric compressive loading. Engineering Structures, 91, pp. 96-111, 2015. https://doi.org/10.1016/j.engstruct.2015.02.032

[2] Corradi, M., Borri, A., Castori, G. \& Sisti, R., Shear strengthening of wall panels through jacketing with cement mortar reinforced by GFRP grids. Composites Part B: Engineering, 64, pp. 33-42, 2014. https://doi.org/10.1016/j.compositesb.2014.03.022

[3] Ismail, N. \& Ingham, J.M., Polymer textiles as a retrofit material for masonry walls. Proceedings of the Institution of Civil Engineers - Structures and Buildings, 167(1), pp. 15-25, 2014. https://doi.org/10.1680/stbu.11.00084

[4] Papanicolaou, C.G., Triantafillou, T.C., Karlos, K. \& Papathanasiou, M., Textilereinforced mortar (TRM) versus FRP as strengthening material of URM walls: in-plane cyclic loading. Materials and Structures, 40(10), pp. 1081-1097, 2007. https://doi.org/10.1617/s11527-006-9207-8

[5] Yardim, Y. \& Lalaj, O., Shear strengthening of unreinforced masonry wall with different fiber reinforced mortar jacketing. Construction and Building Materials, 102, pp. 149-154, 2016. https://doi.org/10.1016/j.conbuildmat.2015.10.095

[6] Foti, D. \& Romanazzi, A., Experimental analysis of fiber-reinforced mortar for walls in rectified brick blocks [Analisi sperimentale di malte fibrorinforzate per pareti in blocchi di laterizio rettificati]. C e Ca, 41(2), pp. 109-118, 2011.

[7] Bilgin, H. \& Korini, O., A new modeling approach in the pushover analysis of masonry structures. International Students' Conference of Civil Engineering, ISCCE, EpokaUniversity, Tirana, Albania, May 2012.

[8] Chaimoon, K. \& Attard, M.M., Modeling of unreinforced masonry walls under shear and compression. Engineering Structures, 29(9), pp. 2056-2068, 2007. https://doi.org/10.1016/j.engstruct.2006.10.019

[9] Gabor, A., Ferrier, E., Jacquelin, E. \& Hamelin, P., Analysis and modelling of the inplane shear behaviour of hollow brick masonry panels. Construction and Building Materials, 20(5), pp. 308-321, 2006.

https://doi.org/10.1016/j.conbuildmat.2005.01.032

[10] Akhaveissy, A.H., The DSC model for the nonlinear analysis of in-plane loaded masonry structures. The Open Civil Engineering Journal, 6(1), pp. 200-214, 2012. https://doi.org/10.2174/1874149501206010200

[11] Koutas, L., Triantafillou, T. \& Bousias, S., Analytical modeling of masonry-infilled RC frames retrofitted with textile-reinforced mortar. Journal of Composites for Construction, pp. 1-14, 2014.

[12] Lee, J.S., Pande, G.N., Middleton, J. \& Kralj, B., Numerical modelling of brick masonry panels subject to lateral loadings. Computers \& Structures, 61(4), pp. 735-745, 1996. https://doi.org/10.1016/0045-7949(95)00361-4

[13] Foti, D., On the numerical and experimental strengthening assessment of tufa masonry with FRP. Mechanics of Advanced Materials and Structures, 20(2), pp. 163-175, 2013. https://doi.org/10.1080/15376494.2012.743634 
[14] SAP2000, v. 14, Computers and Structures, Inc. Structural Sotware for analysis and Design, Berkeley, CA, USA, 2012.

[15] Corradi, M., Borri, A. \& Vignoli, A., Experimental study on the determination of strength of masonry walls. Construction and Building Materials, 17(5), pp. 325-337, 2003.

https://doi.org/10.1016/s0950-0618(03)00007-2

[16] Corradi, M., Tedeschi, C., Binda, L. \& Borri, A., Experimental evaluation of shear and compression strength of masonry wall before and after reinforcement: deep repointing. Construction and Building Materials, 22(4), pp. 463-472, 2008. https://doi.org/10.1016/j.conbuildmat.2006.11.021

[17] EN 1052-1, Methods of test for masonry - Part 1: Determination of compressive strength. European Committee for standardization, p. 11, 1999.

[18] ASTM E519/E519M. Standard Test Method for Diagonal Tension (Shear) in masonry assemblages. ASTM International, West Conshohocken, PA, 2010. 